\title{
Will the Kraepelinian Dichotomy Survive DSM-V?
}

\author{
Bernard A Fischer' and William T Carpenter Jr*,' \\ 'Department of Psychiatry, Maryland Psychiatric Research Center, VA Capitol Health Care Network (VISN 5) MIRECC \& University of Maryland \\ School of Medicine, Baltimore, MD, USA
}

\begin{abstract}
Kraepelin proposed dementia praecox and manic-depressive illness as the two major psychotic disorders. This paradigm is still prevalent, but observations of overlapping boundaries between bipolar disorder and schizophrenia challenge this dichotomy. However, the concept of schizophrenia has been radically altered from the original Kraepelinian proposal. We defend the two psychoses positions, but suggest two flaws in the heuristic application: (I) overlapping features, such as psychotic symptoms, are not decisive in differential diagnosis; and (2) each disorder is a syndrome, not a disease entity. An alternative paradigm based on domains of pathology is more powerful for studies of etiology, pathophysiology, and therapeutic discovery.

Neuropsychopharmacology (2009) 34, 208I-2087; doi:10.1038/npp.2009.32; published online 18 March 2009
\end{abstract}

Keywords: diagnosis; psychosis; kraepelin; schizophrenia; bipolar disorder; DSM-V

\section{INTRODUCTION}

Over 100 years ago Kraepelin conceptualized dementia praecox and manic-depressive psychosis as two distinct diseases. This dichotomy continues today in the nosological classes of schizophrenia and the bipolar disorders. However, many similarities between these two classes have been noted and the validity and heuristic value of this dichotomy is in question, especially when recent genetic findings are considered (Lake, 2008; Craddock and Owen, 2005; Moller, 2003). With the Diagnostic and Statistical Manual of Mental Disorders (DSM) set to undergo some significant changes in its fifth edition, the time is right to explore whether Kraepelin's dichotomy remains a useful concept. (Dr Carpenter chairs the work group for psychotic disorders and is a member of the task force for DSM-V. The opinions expressed here are those of the authors and do not represent views or actions of the DSM-V work group.) We defend the position of separate disorders and point out two major problems in joining the diagnoses. We explain why overlapping features, including psychosis, are not decisive in the debate. We also posit that each disorder is a clinical syndrome rather than a specific disease entity. As such, a 'domains of pathology' approach is a more heuristic paradigm for etiological, pathophysiological, and therapeu-

\footnotetext{
*Correspondence: Dr W Carpenter Jr, Department of Psychiatry, VA Capitol Health Care Network (VISN 5) MIRECC \& University of Maryland School of Medicine, Maryland Psychiatric Research Center, PO Box 21247, Baltimore, Maryland 21228, USA,

Tel: + 4104027101 , Fax: + 4107883837 ,

E-mail: wcarpent@mprc.umaryland.edu

Received 14 November 2008; revised 4 February 2009; accepted 6 February 2009
}

tical discovery, and may clarify points of similarity and decisive differences between the two syndromes.

\section{PROBLEM NO. 1: PSYCHOSIS}

The problem with using psychosis, especially reality distortion symptoms such as delusions and hallucinations, to define a disease entity is simple. Psychosis is a common manifestation of many diseases that are distinguished at the level of etiology. Causes of psychotic experience range from sensory isolation to temporal lobe epilepsy, and a number of psychotic conditions have known causes (eg, PCP psychosis or Huntington's disease). Psychosis is on a continuum in human experience and is not uncommon in population surveys (Rossler et al, 2007; van Os et al, 2000; Kendler et al, 1996). Psychosis also occurs in circumstances not considered pathological (eg, religious ecstasy). Defining psychosis as an illness has required secondary criteria relating to disability and/or distress. But for schizophrenia and bipolar illnesses, disability and discomfort are more robustly associated with cognitive impairments, negative symptoms (in schizophrenia), and mood pathology (in bipolar disorder).

Indeed, the brain generates hallucinations and delusions in so many conditions that it is difficult to understand how these symptoms have maintained primacy in the diagnosis of any specific disease. Psychotic experience is to the diagnosis of mental illness as fever is to the diagnosis of infection-important, but non-decisive in differential diagnosis.

Some studies contrasting schizophrenia and bipolar disorder document important differences. For example, McIntosh et al (2008) probe language dysfunction and observe decreased brain activation in both disorders, but an 
anatomic distinction with anterior insula in bipolar disorder and dorsal prefrontal cortex in schizophrenia. Nonetheless, the boundary between the two major psychoses is porous. Hallucinations, delusions, and disordered thoughts are observed in both. Similar forms of symptoms may be phenomenologically distinguished (eg, pressured thought in mania and dissociative thought in schizophrenia; mood congruent delusions in bipolar disorder and more bizarre delusions in schizophrenia (Solovay et al, 1987; Shenton et al, 1987)), and causal mechanisms may be different even if the neural substrate is similar. With important similarities and differences, the paramount issue is whether the two diagnostic classes comprise one heterogeneous disorder with an artificial boundary or two disorders with overlapping features.

The challenge to the Kraepelinian dichotomy may not have become relevant had the core pathological features, which originally distinguished dementia praecox and manic-depressive psychosis, survived in DSM-III and -IV. Kraepelin (1971/1919) described the two 'general maladies' of dementia praecox: dissociative pathology, that is disorganization of thought and/or behavior, and 'a weakening of the well-springs of volition', ie the negative symptom complex. Blueler (1950/1911) also considered these pathologies fundamental and considered reality distortion symptoms as secondary. The fundamental features of dissociation and avolition were critical in distinguishing schizophrenia from manic-depressive psychosis. Debate as to whether the Kraepelinian dichotomy is valid presumes that the current concept and criteria for schizophrenia relate closely with the original construct. This is not the case. For these pioneers, it was the closely linked dissociative and avolitional pathology that described schizophrenia, and their co-occurrence in individuals that defined caseness. Manic-depressive illness was defined by mood excesses and episodic pattern. A long-term course was also discriminating. This is in contrast with the DSM-III and -IV criteria. The presence of hallucinations and delusions, or just delusions if bizarre, satisfies criterion A for schizophrenia even in the absence of dissociative and avolitional pathologies. Avolition was not even included as a criterion in DSM-III.

In an effort to improve diagnostic reliability, Schneider (1959) proposed that certain reality distortion symptoms (referred to as first-rank symptoms) were highly characteristic of schizophrenia. In Europe, coupled with the distinction of Langfeldt's (1969) between true and pseudoschizophrenia, these concepts gelled in the concept of 'nuclear' schizophrenia. During this time in the United States, scientists from Washington University were organizing diagnoses with explicit criteria and validation based on onset, manifest pathology, course, treatment, and associated biological features. This approach, modified and put forward as the Research Diagnostic Criteria by Spitzer et al (1979), joined the European nuclear schizophrenia tradition as the foundation for the DSM-III approach to psychoses. However, in the transition from Kraepelin/ Bleuler to DSM-III, the concept of schizophrenia has been remarkably altered.

The fact that the original conceptualization of schizophrenia differs from current diagnostic criteria does not automatically indicate that the current system is flawed.
However, studies conducted during the late 1960s and the early 1970s tested several versions of the nuclear schizophrenia concept and suggested just such a conclusion. Firstrank symptoms were observed in psychotic classes other than schizophrenia (Carpenter and Strauss, 1974; Strauss et al, 1974; Carpenter et al, 1973b); none of the definitions of nuclear schizophrenia based on supposedly pathognomonic reality distortion symptoms predicted course and outcome (Hawk et al, 1975; Strauss and Carpenter, 1974a, b; Carpenter et al, 1973a), and functional outcomes were mainly related to other aspects of the syndrome (Hawk et al, 1975; Strauss and Carpenter, 1974a,b; Carpenter et al, 1973a). The most robust symptomatic distinctions between schizophrenia and non-schizophrenia psychotic diagnostic classes were restricted affect, poor rapport, and poor insight (Carpenter et al, 1973a). For DSM-III, presumptions of validity of the nuclear schizophrenia concept trumped this empirical data, falsifying the key hypotheses relating to the Schneiderian and Langfeldt systems. This shift in concept has profound implications and moves bipolar illness and schizophrenia closer together by emphasizing common features while de-emphasizing the pathological attributes that originally distinguished the conditions.

Kraepelin also distinguished manic depression from dementia praecox based on course, the former being cyclical and the latter chronic. Does this difference carry any nosological information in an era of chronic mania (Malhi et al, 2001) and remission/recovery in schizophrenia (Fischer and Carpenter, 2008)? Two current issues complicate the testing of Kraepelin's original observation. The first is the concept alteration in our modern diagnostic scheme. Recent longitudinal studies in schizophrenia use diagnostic criteria that emphasize psychosis and do not require avolitional pathology. Restricted affect was the most robust predictor of poor 5-year outcome in the Washington Center of the International Pilot Study of Schizophrenia (Carpenter et al, 1978), and prominent negative symptoms are associated with a more chronic course (Strauss et al, 2008; Moller et al, 2002). The second issue is therapeutic intervention. From the mid-20th century onward, treatment has been robustly influenced by movement away from chronic institutionalization and by pharmacotherapy. Nonetheless, longitudinal data from pre- and post-antipsychotic drug eras reveal heterogeneity of course for schizophrenia (Marengo, 1994). As most studies follow cohorts of already chronic cases, a bias toward chronic morbidity is present and good outcome cases may be excluded. A typical course for schizophrenia is difficult to define, let alone use as a validating criterion for classification. The course pattern early in bipolar disorder is primarily mood pathology and episodic, but a long-term follow-up also reports eventual chronic course. Course heterogeneity in each condition precludes identification of a 'typical' course that can validate diagnostic classification.

\section{PROBLEM NO. 2: SYNDROMES vs DISEASE ENTITIES}

The debate over whether schizophrenia and bipolar disorder are one disease or two is based on the assumption that each diagnosis is homogeneous enough to consider the combination. But there has been no documentation of a 
unifying etiopathophysiology within either schizophrenia or bipolar disorder. If this were the case, the debate would be settled by determining whether the specific pathological causal pathway is the same for both diagnostic classes. However, each diagnosis is likely a clinical syndrome comprising several specific disease entities. The hypothesis that deficit schizophrenia represents a separate disease within the syndrome of schizophrenia illustrates this concept (Kirkpatrick et al, 2001; Carpenter et al, 1988). The realization that schizophrenia and bipolar disorders have syndrome status shifts the question to whether there is a disease entity within one of the syndromes that is a better fit in the other syndrome, and, if so, how cases will be identified.

Consider asking whether dementia and delirium are one disease or two. Sharing some prominent cognitive impairment would not justify the question. The heterogeneity within each syndrome would undermine any investigation designed to answer the one-disease-or-two question. Dementia with Alzheimer's disease removed is a different syndrome. Remove multi-infarct dementia, and the syndrome is now more narrowly defined, but still a heterogeneous condition comprising pernicious anemia dementia, dementia associated with traumatic brain injury, Parkinson's disease, and other discrete conditions. Most investigations of schizophrenia and bipolar disorders are conducted as though a disease entity has been defined. Unlike dementia and delirium, the tools to reduce heterogeneity of these two mental illness syndromes are not yet clearly established. Nonetheless, study designs that treat a syndrome as though it were a specific disease entity provide a weak methodology for decisive hypothesis testing (Carpenter et al, 1993).

Studies within schizophrenia that contrast subjects with and without primary negative symptoms (deficit $v s$ nondeficit schizophrenia) reveal differences in some clinical features (eg, vulnerability to depression and substance abuse) while being similar in psychotic symptoms (Kirkpatrick et al, 1994, 1996; Fenton and McGlashan, 1994; Kirkpatrick and Buchanan, 1990). Importantly, risk factors (eg, an excess of summer births in the deficit syndrome as opposed to late winter-early spring births in schizophrenia in general (Messias et al, 2004; Kirkpatrick et al, 1998, 2000, 2002a, b; Tek et al, 2001; Messias and Kirkpatrick, 2001)) and neuropathology (Kirkpatrick et al, 1999, 2003) seem to distinguish the two forms of schizophrenia. Results of comparing bipolar subjects with schizophrenia subjects would be quite different on key variables if the schizophrenia cohort is exclusively deficit or exclusively non-deficit.

In principle, the question of one disease or two is meaningless if each construct subsumes two or more entities that are importantly distinct from each other. This seems to be the case in schizophrenia (Tandon and Maj, 2008) and is likely the case in bipolar disorder as well (Potash et al, 2001, 2003; Akiskal and Pinto, 1999).

\section{A HEURISTIC MODEL AS AN ALTERNATIVE TO SYNDROME OR DISEASE ENTITY}

There are many features commonly observed in cases within both schizophrenia and mood disorders, such as anxiety, depression, reality distortion, insomnia, and cognitive impairment. Family pedigree studies generally support the dichotomy, but linkage and association studies suggest overlap or shared genetic vulnerability (Berrettini, 2000). Endophenotypes have been identified in both syndromes, often overlapping, sometimes not (Ivleva et al, 2008; Hill et al, 2008; Thaker, 2008). Consider this thought experiment:

a. risk alleles for genes $x, y$, and $z$ have been identified for hallucinatory experience in the general population;

b. these risk alleles distinguish bipolar from non-ill controls;

c. these risk alleles distinguish schizophrenia from non-ill controls;

d. the association is stronger in schizophrenia compared with that in bipolar disorder.

This pattern of finding seems plausible, but would not suggest that the two illness syndromes are the same disease. Rather, it would suggest that hallucinatory behavior is associated with risk genes across cohorts that differ in the proportion of hallucinating subjects. Testable hypotheses include (a) risk alleles for genes $x, y$, and $z$ will distinguish bipolar subjects with hallucinations from bipolar subjects without a history of hallucinations and (b) overlap between schizophrenia and bipolar associations to these risk alleles will increase if all subjects in each class are required to have a history of hallucinations. How, then, should the field proceed to advance knowledge on the relationships among the diseases contained in the two syndromes?

One approach is illustrated by Owen et al (2007) in their genetic deconstruction of psychosis. They propose that overlapping genes, such as DISC1 and NRG1, contribute to psychotic and mood pathology and that other genes (eg, $D A O A$ and $B D N F$ ) lead to the mood disorders prototype. Genes for proteins such as Dysbindin would move the picture toward typical schizophrenia. This concept places the psychotic disorders on a continuum, with differential etiopathophysiological factors defining the two extremes. If mood and psychotic features are central, this is compatible with one disease with different co-morbid pathologies at the two extremes. If the pathologies at the two extremes are considered central to diagnostic class, this model would imply that mood disorder and schizophrenia are separate diseases with a shared psychotic and mood pathology. A more explicit approach to this second alternative is the 'domains of pathology' paradigm (Strauss et al, 1974; Carpenter and Buchanan, 1989). Breaking down each diagnostic class into domains of pathology gives more specificity to developing treatments and elucidating etiopathophysiology. The unit of study moves from diagnostic classes with porous boundaries to specific psychopathologies, which are important to class, but not unique. Rather than study designs confounded by porous boundaries, the pathological domains become the focus even though observed in more than one class (and not necessarily in all subjects within a class).

Genetic studies can be refined using a domain-based approach. Inconsistency in replication is expected when heterogeneous syndromes are studied. This inconsistency has been the case in schizophrenia. A focus on certain pathological domains to make samples more homogeneous may lead to more consistent findings and, therefore, to a 
better understanding of the genetic etiology of diseases. This appears to be the case in preliminary studies in which a different pattern of morbid risk was observed between deficit schizophrenia probands and non-deficit schizophrenia probands (Kirkpatrick et al, 2001).

Indeed, an analysis of genetic data using latent class analysis to identify subgroups of psychosis revealed genes associated with the deficit subgroup that were not observed when data were analyzed by diagnostic class (Fanous et al, 2008). Endophenotypes (Gottesman and Gould, 2003) may be even more decisive in this regard (Braff et al, 2007; Calkins et al, 2007; Gur et al, 2007a, b; Turetsky et al, 2007; Aukes et al, 2008; Javitt et al, 2008; Thaker, 2007; Freedman et al, 1999) and were critical in identifying an $\alpha-7$ nicotinic receptor gene on chromosome 15 as a candidate for involvement in schizophrenia pathology (Freedman et al, 1997). A recent study by Thaker (2008) describes the current status and challenges involved in the application of endophenotypes across bipolar disorder and schizophrenia.

Genes that confer risk for both bipolar disorder and schizophrenia may best be understood at the level of a specific psychopathological dimension. The general hypothesis is that shared risk factors and pathophysiology will be associated with domains of pathology that overlap between classes. Non-shared risk factors and pathophysiology will be associated with non-overlapping pathology. The importance of addressing these issues is made clear by Lichtenstein et al (2009) in a study of over 76000 schizophrenia and bipolar probands and their families. In the best estimate to date, about $60 \%$ of the variance in each group is attributed to genetic factors, about equally divided between shared and unique genetic effects. Do the unique factors simply add to liability for diagnostic class, or are they more specifically related to domains such as avolition in schizophrenia and episodic affect disruption in bipolar disorder? It remains to be determined which pathologies are critical for diagnostic class or, for that matter, how classification will be revised based on new data related to this paradigm shift.

Another crucial issue comes from the observation that people with both schizophrenia and bipolar disorder show cognitive impairments. In general, people with schizophrenia have worse cognitive impairment than people with bipolar disorder (Keefe and Fenton, 2007; Krabbendam et al, 2005). Cognitive impairments in schizophrenia are observed during pre-psychotic development and are remarkably constant in individuals over the course of their illness, whereas cognitive impairments in mood disorders have shown variability depending on the phase of illness (Keefe and Fenton, 2007; Hill et al, 2008). However, evidence is accumulating that, among mood disorders, the presence of psychosis indicates worse cognitive impairment, and people with psychotic bipolar disorder show cognitive impairment similar to that observed in schizophrenia (Seidman et al, 2002; Glahn et al, 2006, 2007). Impaired cognition associated with bipolar disorder has also recently been observed during non-medicated and euthymic states and in first-degree relatives, suggesting at least a subtle trait impairment (Malhi et al, 2007; Pavuluri et al, 2006; Bora et al, 2008). Is impaired cognition in the two disorders based on the shared genetic effects with greater load for schizophrenia, or does similarity of impairment represent a common final pathway based on unique genetic or environmental effects?

Similarly, vulnerability genes for depressed mood may be shared among depressed cases in both syndromes. Kempf et al (2005) conclude that dimensions are the critical unit of analysis when comparing mood-disordered schizophrenia subjects with major mood disorder subjects experiencing psychosis. Another interesting example is reported by McDonald et al (2004), who reduced syndrome heterogeneity by relating genetic risk for schizophrenia or for bipolar disorder with brain structural endophenotypes. Anatomical variations in white matter overlapped between the two disorders, whereas each disorder was associated with a distinctive pattern of variation in gray matter.

The examples above help clarify differences in scientific methodology used to address observations of porous boundaries between current diagnostic classes. We propose that it is data at the level of pathological domains rather than syndrome class that will provide the information critical to re-conceptualizing nosology and advancing knowledge on biomarkers and therapeutic targets. This approach pre-supposes that unique effects are associated with pathological processes that occur in several diagnostic classes, but in substantially different proportions (eg, depression is ubiquitous in mood disorders and less frequent in schizophrenia). An alternative supposition is that unique factors combine with shared factors to create distinctive diagnostic classes and that porous boundaries are caused by the shared factors rather than pathological domains in different proportions.

\section{CONCLUSIONS}

The question as to whether schizophrenia and bipolar disorder are one disease or two is relevant only if, in fact, these are two diseases at most. If either or both are a syndrome comprising several disease entities, the question is two or more, not two or less. If these classes are syndromes, then their combination creates a broader and more heterogeneous syndrome. This will decrease robustness of study designs, lead to type II error, and be an unnecessary impediment to hypothesis testing.

To ask the question in the dichotomous, Kraepelinian context ignores the remarkable alteration in diagnosis associated with modern criteria. Furthermore, psychosis is a 'final common pathway' produced by the brain in response to many different insults. Similarity across diagnostic classes based on psychotic symptoms may not be more definitive than similarity in anxiety across different classes.

We propose that the current separation of schizophrenia and bipolar disorder into two syndromes captures some important distinctions. However, much more information is needed to determine the critical areas of similarity and difference. For this purpose, the domains of pathology paradigm provide a heuristic unit of analysis. A number of critical dimensions can be proposed for each syndrome.

The failure to make use of 'strong inference' in psychiatry has contributed to the slow pace of advancement in the field (Carpenter et al, 1993). Platt (1964) proposed that scientific fields with the most rapid progress design studies in which 
the data can force theory modification and move the field to the next branch point. A century of research on psychoses has been rich in hypothesis generation and slender on theory falsification. Data have not yet been produced to decisively falsify the Kraepelinian dichotomy or even to identify specific disease entities within the major syndromes. Heterogeneity reduction in syndromes is essential.

It seems very likely that DSM-V will take the approach of maintaining current classes of disorders with refined criteria while bringing a new emphasis to the domains of pathology paradigm (Regier, 2007; van Os and Tamminga, 2007; Allardyce et al, 2007; Dutta et al, 2007; Keller et al, 2007; Owen et al, 2007; Gur et al, 2007a, b). Research in this context will then clarify similarities and differences at the domain or dimension level. Only then will the field be sufficiently informed to radically re-conceptualize classification of what we identify today as the psychotic and mood disorders.

\section{ACKNOWLEDGEMENTS}

This work was supported by NIH 1P50 MH082999 (CIDAR) PI toWTC and NIH 5T32 MH67533 (T32 Training Grant) PI to WTC and Fellow BAF, a 2008 NARSAD Young Investigator Award to BAF and a 2008 NARSAD Distinguished Investigator Award to WTC, and by the VISN 5 VA Mental Illness Research, Education and Clinical Center (Alan Bellack, PI).

\section{CONFLICT OF INTEREST}

BAF: none. WTC: European Regional Patent Number 1487998 (6 June 2007) 'Methods for Diagnosing and Treating Schizophrenia' (any potential compensation pledged to the University of Baltimore Foundation). In 2006-2008, Dr Carpenter has been an advisor to, or prepared educational material for, Merck, McNeil, Pfizer, Janssen, Solvay, Wyeth, Astra Zeneca, Lilly, Cephalon, and Teva. No conflict is presently anticipated for 2009 .

\section{REFERENCES}

Akiskal HS, Pinto O (1999). The evolving bipolar spectrum: prototypes I, II, III, and IV. Psychiatr Clin North Am 22: 517-534.

Allardyce J, Gaebel W, Zielasek J, van Os J (2007). Deconstructing Psychosis Conference February 2006: the validity of schizophrenia and alternative approaches to the classification of psychosis. Schizophr Bull 33: 863-867.

Aukes MF, Alizadeh BZ, Sitskoorn MM, Selten JP, Sinke RJ, Kemner C et al (2008). Finding suitable phenotypes for genetic studies of schizophrenia: heritability and segregation analysis. Biol Psychiatry 64: 128-136.

Berrettini WH (2000). Are schizophrenic and bipolar disorders related? A review of family and molecular studies. Biol Psychiatry 48: 531-538.

Blueler E (1950). Dementia Praecox or the Group of Schizophrenias. International Universities Press: New York. [first published, 1911.].

Bora E, Vahip S, Akdeniz F, Ilerisoy H, Aldemir E, Alkan M (2008). Executive and verbal working memory dysfunction in first-degree relatives of patients with bipolar disorder. Psychiatry Res 161: 318-324.
Braff DL, Freedman R, Schork NJ, Gottesman II (2007). Deconstructing schizophrenia: an overview of the use of endophenotypes in order to understand a complex disorder. Schizophr Bull 33: 21-32.

Calkins ME, Dobie DJ, Cadenhead KS, Olincy A, Freedman R, Green MF et al (2007). The consortium on the genetics of endophenotypes in schizophrenia: model recruitment, assessment, and endophenotyping methods for a multisite collaboration. Schizophr Bull 33: 33-48.

Carpenter Jr WT, Bartko JJ, Strauss JS, Hawk AB (1978). Signs and symptoms as predictors of outcome: a report from the International Pilot Study of Schizophrenia. Am J Psychiatry 135: 940-945.

Carpenter WT, Buchanan RW (1989). Domains of pathology relevant to the study of etiology and treatment of schizophrenia. In: Schulz SC, Tamminga CT (eds). Schizophrenia: Scientific Progress. Oxford University Press: New York. pp 13-22.

Carpenter Jr WT, Buchanan RW, Kirkpatrick B, Tamminga C, Wood F (1993). Strong inference, theory testing, and the neuroanatomy of schizophrenia. Arch Gen Psychiatry 50: 825-831.

Carpenter Jr WT, Heinrichs DW, Wagman AMI (1988). Deficit and non-deficit forms of schizophrenia: the concept. Am J Psychiatry 145: 578-583.

Carpenter WT, Strauss JS (1974). Cross-cultural evaluation of Schneider's first rank symptoms of schizophrenia: a report from the International Pilot Study of Schizophrenia. Am J Psychiatry 131: 682-687.

Carpenter WT, Strauss JS, Bartko JJ (1973a). A flexible system for the identification of schizophrenia: a report from the International Pilot Study of Schizophrenia. Science 182: 1275-1278.

Carpenter WT, Strauss JS, Muleh S (1973b). Are there pathognomonic symptoms in schizophrenia? An empiric investigation of Kurt Schneider's first rank symptoms. Arch Gen Psychiatry 28: 847-852.

Craddock N, Owen MJ (2005). The beginning of the end for the Kraepelinian dichotomy. Br J Psychiatry 186: 364-366.

Dutta R, Greene T, Addington J, McKenzie K, Phillips M, Murray RM (2007). Biological, life course, and cross-cultural studies all point toward the value of dimensional and developmental ratings in the classification of psychosis. Schizophr Bull 33: 868-876.

Fanous AH, Neale MC, Webb BT, Straub RE, O’Neill FA, Walsh D et al (2008). Novel linkage to chromosome 20p using latent classes of psychotic illness in 270 Irish high-density families. Biol Psychiatry 64: 121-127.

Fenton WS, McGlashan TH (1994). Antecedents, symptoms progression, and long-term outcome of the deficit syndrome in schizophrenia. Am J Psychiatry 151: 351-356.

Fischer BA, Carpenter WT (2008). Remission. In: Mueser KM, Jeste DV (eds). Clinical Handbook of Schizophrenia. Guilford Press: New York. pp 559-565.

Freedman R, Adler LE, Leonard S (1999). Alternative phenotypes for the complex genetics of schizophrenia. Biol Psychiatry 45: 551-558.

Freedman R, Coon H, Myles-Worsley M, Orr-Urtreger A, Olincy A, Davis A et al (1997). Linkage of a neurophysiological deficit in schizophrenia to a chromosome 15 locus. Proc Natl Acad Sci USA 94: 587-592.

Glahn DC, Barrett J, Bearden CE, Mintz J, Green MF, Serap Monkul E et al (2006). Dissociable mechanisms for memory impairment in bipolar disorder and schizophrenia. Psychol Med 36: 1085-1095.

Glahn DC, Bearden CE, Barguil M, Barrett J, Reichenberg A, Bowden CL et al (2007). The neurocognitive signature of psychotic bipolar disorder. Biol Psychiatry 62: 910-916.

Gottesman II, Gould TD (2003). The endophenotype concept in psychiatry: etymology and strategic intentions. Am J Psychiatry 160: 636-645. 
Gur RE, Calkins ME, Gur RC, Horan WP, Nuechterlein KH, Seidman LJ et al (2007a). The consortium on the genetics of schizophrenia: neurocognitive endophenotypes. Schizophr Bull 33: 49-68.

Gur RE, Keshavan MS, Lawrie SM (2007b). Deconstructing psychosis with human brain imaging. Schizophr Bull 33: 921-931.

Hawk AB, Carpenter WT, Strauss JS (1975). Diagnostic criteria and 5 -year outcome in schizophrenia: a report from the International Pilot Study of Schizophrenia. Arch Gen Psychiatry 32: 343-356.

Hill SK, Harris MSH, Herbener ES, Pavuluri M, Sweeney JA (2008). Neurocognitive allied phenotypes for schizophrenia and bipolar disorder. Schizophr Bull 34: 743-759.

Ivleva E, Thaker G, Tamminga CA (2008). Comparing genes and phenomenology in the major psychoses: schizophrenia and bipolar 1 disorder. Schizophr Bull 34: 734-742.

Javitt DC, Spencer KM, Thaker GK, Winterer G, Hajos M (2008). Neurophysiological biomarkers for drug development in schizophrenia. Nat Rev Drug Discov 7: 68-83.

Keefe RSE, Fenton WS (2007). How should DSM-V criteria for schizophrenia include cognitive impairment? Schizophr Bull 33: 912-920.

Keller J, Schatzberg AF, Maj M (2007). Current issues in the classification of psychotic major depression. Schizophr Bull 33: 877-885.

Kempf L, Hussain N, Potash JB (2005). Mood disorder with psychotic features, schizoaffective disorder, and schizophrenia with mood features: trouble at the borders. Int Rev Psychiatry 17: 9-19.

Kendler KS, Gallagher TJ, Abelson JM, Kessler RC (1996). Lifetime prevalence, demographic risk factors, and diagnostic validity of nonaffective psychosis as assessed in a US community sample. The National Comorbidity Survey. Arch Gen Psychiatry 53: 1022-1031.

Kirkpatrick B, Amador XF, Flaum M, Yale SA, Gorman JM, Carpenter WT et al (1996). The deficit syndrome in the DSM-IV Field Trial, I: alcohol and other drug abuse. Schizophr Res 20: 69-77.

Kirkpatrick B, Buchanan RW (1990). Anhedonia and the deficit syndrome of schizophrenia. Psychiatry Res 31: 25-30.

Kirkpatrick B, Buchanan RW, Breier A, Carpenter Jr WT (1994). Depressive symptoms and the deficit syndrome of schizophrenia. J Nerv Ment Dis 182: 452-455.

Kirkpatrick B, Buchanan RW, Ross DE, Carpenter Jr WT (2001). A separate disease within the syndrome of schizophrenia. Arch Gen Psychiatry 58: 165-171.

Kirkpatrick B, Castanedo SH, Valquez-Barquero JL (2002a). Summer birth and deficit schizophrenia: Cantabria, Spain. $J$ Nerv Ment Dis 190: 526-532.

Kirkpatrick B, Castle D, Murray RM, Carpenter Jr WT (2000). Risk factors for the deficit syndrome of schizophrenia. Schizophr Bull 26: 233-242.

Kirkpatrick B, Conley RR, Kakoyannis A, Reep RL, Roberts RC (1999). The interstitial cells of the white matter in the inferior parietal cortex in schizophrenia: an unbiased cell-counting study. Synapse 34: 95-102.

Kirkpatrick B, Messias NC, Conley RR, Roberts RC (2003). Interstitial cells of the white matter in the dorsolateral prefrontal cortex in deficit and nondeficit schizophrenia. J Nerv Ment Dis 191: $563-567$.

Kirkpatrick B, Ram R, Amador XF, Buchanan RW, McGlashan T, Tohen $\mathrm{M}$ et al (1998). Summer birth and the deficit syndrome of schizophrenia. Am J Psychiatry 155: 1221-1226.

Kirkpatrick B, Tek C, Allardyce J, Morrison G, McCreadie RG (2002b). Summer birth and deficit schizophrenia in Dumfries and Galloway, Southwestern Scotland. Am J Psychiatry 150: 1382-1387.

Krabbendam L, Arts B, van Os J, Aleman A (2005). Cognitive functioning in patients with schizophrenia and bipolar disorder: a quantitative review. Schizophr Res 80: 137-149.
Kraepelin E (1971). Dementia Praecox and Paraphrenia. Krieger: New York. [first published, 1919.].

Lake CR (2008). Disorders of thought are severe mood disorders: the selective attention deficit in mania challenges the Kraepelinian Dichotomy - A review. Schizophr Bull 34: 109-117.

Langfeldt G (1969). Schizophrenia: diagnosis and prognosis. Behav Sci 14: 173-182.

Lichtenstein P, Yip BH, Bjork C, Pawitan Y, Cannon TD, Sullivan $\mathrm{PF}$ et al (2009). Common genetic determinants of schizophrenia and bipolar disorder in Swedish families: a population-based study. Lancet 373: 234-239.

Malhi GS, Ivanovski B, Hadzi-Pavlovic D, Mitchell PB, Vieta E, Sachdev P (2007). Neuropsychological deficits and functional impairment in bipolar depression, hypomania and euthymia. Bipolar Disord 9: 114-125.

Marengo J (1994). Classifying the courses of schizophrenia. Schizophr Bull 20: 519-536.

Messias E, Kirkpatrick B (2001). Summer birth and deficit schizophrenia in the epidemiological catchment area study. J Nerv Ment Dis 189: 608-612.

McDonald C, Bullmore ET, Sham PC, Chitnis X, Wickham H, Bramon E et al (2004). Association of genetic risks for schizophrenia and bipolar disorder with specific and generic brain structural endophenotypes. Arch Gen Psychiatry 61: 974984.

McIntosh AM, Whalley HC, McKirdy J, Hall J, Sussmann JE, Shankar $\mathrm{P}$ et al (2008). Prefrontal function and activation in bipolar disorder and schizophrenia. Am J Psychiatry 165: 378-384.

Messias E, Kirkpatrick B, Bromet E, Ross D, Buchanan RW, Carpenter Jr WT et al (2004). Summer birth and deficit schizophrenia: a pooled analysis from 6 countries. Arch Gen Psychiatry 61: 985-989.

Malhi GS, Mitchell PB, Parker GB (2001). Rediscovering chronic mania. Acta Psychiatr Scand 104: 153-156.

Moller HJ (2003). Bipolar disorder and schizophrenia: distinct illnesses or a continuum? J Clin Psychiatry 64(Suppl 6): 23-27.

Moller HJ, Bottlender R, Gross A, Hoff P, Wittmann J, Wegner U et al (2002). The Kraepelinian dichotomy: preliminary results of a 15-year follow-up study on functional psychoses: focus on negative symptoms. Schizophr Res 56: 87-94.

Owen MJ, Craddock N, Jablensky A (2007). The genetic deconstruction of psychosis. Schizophr Bull 33: 905-911.

Pavuluri MN, Schenkel LS, Aryal S, Harral EM, Hill SK, Herbener ES et al (2006). Neurocognitive function in unmedicated manic and medicated euthymic pediatric bipolar patients. Am J Psychiatry 163: 286-293.

Platt JR (1964). Strong inference. Science 146: 347-353.

Potash JB, Chiu YF, MacKinnon DF, Miller EB, Simpson SG, McMahon FJ et al (2003). Familial aggregation of psychotic symptoms in a replication set of 69 bipolar disorder pedigrees. Am J Med Genet B Neuropsychiatr Genet 116: 90-97.

Potash JB, Willour VL, Chiu YF, Simpson SG, MacKinnon DF, Pearlson GD et al (2001). The familial aggregation of psychotic symptoms in bipolar disorder pedigrees. Am J Psychiatry 158: $1258-1264$.

Regier D (2007). Time for a fresh start? Rethinking psychosis in DSM-V. Schizophr Bull 33: 843-845.

Rossler W, Riecher-Rossler A, Angst J, Murray R, Gamma A, Eich D et al (2007). Psychotic experiences in the general population: a twenty-year prospective community study. Schizophr Res 92: 1-14.

Schneider K (1959). Clinical Psychopathology. Translated by Hamilton MW. Grune \& Stratton: New York.

Seidman LJ, Kremen WS, Koren D, Faraone SV, Goldstein JM, Tsuang MT (2002). A comparative profile analysis of neuropsychological functioning in patients with schizophrenia and bipolar psychoses. Schizophr Res 53: 31-44. 
Shenton ME, Solovay MR, Holzman P (1987). Comparitive studies of thought disorders: II. Schizoaffective disorder. Arch Gen Psychiatry 44: 21-30.

Solovay MR, Shenton ME, Holzman PS (1987). Comparitive studies of thought disorders: I. Mania and schizophrenia. Arch Gen Psychiatry 44: 13-20.

Spitzer RL, Endicott J, Williams JB (1979). Research diagnostic criteria. Arch Gen Psychiatry 36: 1381-1383.

Strauss GP, Harrow M, Grossman LS, Rosen C (2008). Periods of recovery in deficit syndrome schizophrenia: a 20-year multifollow-up longitudinal study. Schizophr Bull (advance access) doi:10.1093/schbul/sbn167.

Strauss JS, Carpenter WT (1974a). Characteristic symptoms and outcome in schizophrenia. Arch Gen Psychiatry 30: 117-120.

Strauss JS, Carpenter WT (1974b). The prediction of outcome in schizophrenia. II. Relationships between predictor and outcome variables: a report from the International Pilot Study of Schizophrenia. Arch Gen Psychiatry 31: 37-42.

Strauss JS, Carpenter Jr WT, Bartko JJ (1974). An approach to the diagnosis and understanding of schizophrenia: part III.
Speculations on the processes that underlie schizophrenic symptoms and signs. Schizophr Bull 11: 61-79.

Tandon R, Maj M (2008). Nosological status and definition of schizophrenia: some considerations for DSM-V and ICD-11. Asian J Psychiatry 1: 22-27.

Tek C, Kirkpatrick B, Kelly C, McCreadie RG (2001). Summer birth and deficit schizophrenia in Nithsdale, Scotland. J Nerv Ment Dis 189: 613-617.

Thaker GK (2007). Schizophrenia endophenotypes as treatment targets. Expert Opin Ther Targets 11: 1-18.

Thaker GK (2008). Neurophysiological endophenotypes across bipolar and schizophrenia psychosis. Schizophr Bull 34: 760-773.

Turetsky BI, Calkins ME, Light GA, Olincy A, Radant AD, Swerdlow NR (2007). Neuropsychological endophenotypes of schizophrenia: the viability of selected candidate measures. Schizophr Bull 33: 69-94.

van Os J, Hanssen M, Bijl RV, Ravelli A (2000). Strauss (1969) revisited: a psychosis continuum in the general population? Schizophr Res 45: 11-20.

van Os J, Tamminga C (2007). Deconstructing psychosis. Schizophr Bull 33: 861-862. 